\title{
Death Details (human clinical trials) Supplemental Qualifiers Dataset
}

National Cancer Institute

\section{Source}

National Cancer Institute. Death Details (human clinical trials) Supplemental Qualifiers

Dataset. NCI Thesaurus. Code C147197.

A dataset containing supplemental information, specifically non-standard variables, to parent records in the death details (human clinical trials) domain. 